\title{
Removal of mercury(II) from wastewater using poly(vinyl pyrrolidinone)
}

\author{
A. Etorki \& M. Walli \\ Department of Chemistry, University of Al-Fateh, Tripoli, Libya
}

\begin{abstract}
In this study a water soluble polymer, poly(vinyl pyrrolidinone) (PVP), was used for separation and preconcentration of $\mathrm{Hg}$ (II) prior to their analysis by Inductively Coupled Plasma Atomic Emission Spectroscopy (ICP-AES). Poly(vinyl pyrrolidinone) polymers containing a pendant lactam ring which is part of a monomeric repeat unit structure can form complexes with target metal ions via oxygen and nitrogen. The $\mathrm{Hg}(\mathrm{II})$ and polymer solution were mixed and $\mathrm{Hg}(\mathrm{II})$-bound polymer was precipitated upon addition of acetone. Adding saturated $\mathrm{KNO}_{3}$ solution to the sample, by the salting out effect, causes the precipitation to be completed faster with less amount of acetone. The precipitate was separated from the solution and dissolved directly with ultra deionised water. In this way, analyte elements were again transferred into the liquid phase and analysed by ICP-AES. The effects of $\mathrm{pH}$, amount of the polymer, molecular weight of the polymer, $\mathrm{Hg}$ (II) ion concentration and centrifuging time on the recovery of the target metal ion have been investigated. The equilibrium experimental data were fitted to Langmuir and Freundlich isotherms models. The maximum $\mathrm{Hg}(\mathrm{II})$ adsorption capacity from aqueous solutions obtained was 30.4 $\mathrm{mg} / \mathrm{g}$ at $\mathrm{pH}$ of about $\mathrm{pH}$ 6.0. Adsorption of heavy metal ions from artificial waste water was also studied. The adsorption capacities were $26.5 \mathrm{mg} / \mathrm{g}$ for $\mathrm{Hg}$ (II), $20.2 \mathrm{mg} / \mathrm{g}$ for $\mathrm{Cd}(\mathrm{II})$ and $15.3 \mathrm{mg} / \mathrm{g}$ for $\mathrm{Pb}(\mathrm{II})$ with recoveries greater than $97 \%$ and relative standard deviations of lower than $3 \% \mathrm{n}=5$.
\end{abstract}

Keywords: mercury(II) removal, adsorption isotherm, mercury sorption, poly(vinyl pyrrolidinone), Langmuir isotherm, Freundlich isotherm, wastewater. 


\section{Introduction}

Water pollution has become a serious problem nowdays. Both the environment and human beings are exposed to different pollutants (organic pollutants, metal ions, etc.) from waste and potable water. The enormous damage caused by water pollution has led to numerous investigations having as their objective the protection of the threatened environment and living systems through new methods. Mercury is one of the most toxic elements of the environment, because of its high reactivity, its extreme volatility and its relative solubility in water and living tissues [1]. The major sources of mercury pollution in the aquatic environment are chloralkali, paper, oil-refining, electrical, rubber processing and fertilizer industries [2]. Mercury has very high tendency for binding to proteins and it mainly affects the renal and nervous systems. In humans, the initial symptoms include numbness of the lips and limbs. As the sickness progresses, permanent damage is done to the central nervous system, and the victim experiences visual constriction, loss of motor coordination, and in the final stages prior to death, loss of memory, speech, hearing and taste [3]. For these reasons mercury must be removed to very low levels from wastewater generated industries such as metal smelting and caustic chlorine production in mercury cells, metal processing, plating and metal finishing. These effluents require chemical treatment before they can be discharged. Different treatment techniques have been developed to remove either or both dissolved and suspended heavy metal ions from industrial wastewater; these include precipitation-neutralization, and ultrafiltration [4], activated carbon and biosorbent [5], silica gel modified with different ligands [6], liquid extraction and solid liquid extraction [7]. The aim of this study is to investigate the use of a water soluble polymer, poly(vinyl pyrrolidinone) (PVP) for removal of $\mathrm{Hg}(\mathrm{II}), \mathrm{Cd}(\mathrm{II})$ and $\mathrm{Pb}$ (II) from aqueous solutions and wastewaters prior to their determination by Inductively Coupled Plasma Atomic Emission Spectroscopy (ICP-AES). The polymer solution was added to the sample and metal-bound polymer was precipitated by acetone. The precipitate separated from supernatant was dissolved with water and the elements were determined. This method was easy, exactly quantitative, fast and simple and did not need most of the requirements demanded for solid-water insoluble materials.

\section{Experimental}

\subsection{Material and methods}

Deionized doubly distilled water was used to prepare all solutions. Stock solutions of metal ions were prepared from their nitrate salts $\mathrm{Hg}\left(\mathrm{NO}_{3}\right)_{2}$, $\left(\mathrm{Cd}\left(\mathrm{NO}_{3}\right)_{2} \cdot 4 \mathrm{H}_{2} \mathrm{O}\right.$ and $\mathrm{Pb}\left(\mathrm{NO}_{3}\right)_{2}$ (Fluka). All metal working standards were prepared by dissolving appropriate amount of metal salt into deionized water. Nitric acid and sodium hydroxide were both analytical reagents grade (Merck). A $20 \%(\mathrm{w} / \mathrm{v})$ solution of poly(vinyl pyrrolidinone), PVP with different molecular weights: 90,000, 120,000 and 180,000 (Aldrich). The solution of the polymer 
was prepared in deionized doubly distilled water. A saturated solution of potassium nitrate was prepared by dissolving $\mathrm{KNO}_{3}$ (Aldrich) in deionized doubly distilled water.

\subsection{Apparatus}

An atomic emission spectrometer (ICP-AES, Varian, Liberty Series II, and Australia) with an wipro Acer computer was used. A WTW digital $\mathrm{pH} / \mathrm{mV}$ meter (model pH-340-A/SET2) with a combination glass electrode (WTW D82362 Weiheim) was used for all $\mathrm{pH}$ measurements. A Damon model centrifuge equipped to timer and speed control was employed for centrifuging of samples.

\subsection{Sampling}

The tannery wastewater samples were collected in pre-washed (with detergent, deionized doubly distilled water, dilute $\mathrm{HNO}_{3}$ and deionized doubly distilled water respectively) polyethylene bottles from Abe Kammash Industrial Region (Zwara)-Libya. The samples were filtered through Millipore cellulose nitrate membrane of pore size $0.45 \mu \mathrm{M}$. The samples were stored in 1 litre polyethylene bottles and acidified to $1 \%$ with nitric acid and were subsequently stored at $4{ }^{\circ} \mathrm{C}$ in a refrigerator.

\subsection{General procedure}

A measured volume of blank, standard or sample solution was taken in a $50 \mathrm{ml}$ beaker. The $\mathrm{pH}$ of the solutions and samples were adjusted with $0.1 \mathrm{~mol} \mathrm{~L}^{-1}$ of $\mathrm{NaOH}$ or $0.1 \mathrm{~mol} \mathrm{~L}^{-1} \mathrm{HNO}_{3}$ to investigate the effect of the $\mathrm{pH}$ on retention of metal ion with the polymer. Five millilitres of standard or sample solution was taken in a $50 \mathrm{ml}$ centrifuge tube and mixed with $1 \mathrm{ml}$ of saturated $\mathrm{KNO}_{3}$ and 0.5 $\mathrm{ml}$ of the polymer solution (20\%). Then the metal-bound polymer was precipitated by adding $20 \mathrm{ml}$ acetone to sample solution, immediately. In order to speed the up the precipitation, the tube content was centrifuged for $3 \mathrm{~min}$. The supernatant was separated simply by decantation. The precipitate was dissolved in $2 \mathrm{ml}$ of deionized doubly distilled water and aspirated directly into ICP-AES against the blank prepared in the same manner without the addition of metal ions. The maximum loading capacity of the polymer was determined by applying the above procedure with higher concentration of analyte. To obtain a completely metal-free polymer, the procedure was repeated four times. To regenerate the polymer, i.e., to obtain a metal-free polymer again in order to use further in other experiments, after the full procedure was completed, a $3 \mathrm{ml}$ of $4 \mathrm{~mol} \mathrm{~L}^{-1}$ $\mathrm{HNO}_{3}$ was added on to the $1 \mathrm{ml}$ of the solution containing the mixture of dissolved polymer and analyte elements which remained from a previous procedures. The polymer was used in other experiments again.

\subsection{Constants}

The adsorption capacity, removal percentage, distribution ratio and selectivity coefficient were calculated, respectively according to literature review reference [8]. 


\section{Results and discussion}

\subsection{Effect of molecular weight of PVP on precipitation and dissolution}

The molecular weight of the polymer has opposite effects on its ease of precipitation in acetone and dis-solution in water. If the molecular weight of the polymer is increased, it is more easily and completely precipitated with a smaller amount of acetone, whereas the dissolution of precipitate with water becomes harder. To use a PVP with a higher molecular weight is more convenient in terms of precipitation but less favourable concerning dissolution. We found that the PVP with a molecular weight of 120,000 was optimal with respect to both precipitation and dissolution properties. Adding saturated $\mathrm{KNO}_{3}$ solution to the sample, by salting effect, cause that the precipitation is completed faster with less amount of acetone, and the precipitate is been bulky and easy to separate. Various salts were tested and $\mathrm{KNO}_{3}$ was selected due to its high solubility in water and absence of interferences.

\subsection{Effect of acetone/sample ratio on precipitation}

The ratio of acetone to aqueous phase volumes is another important parameter for complete and bulky precipitation of PVP. If the ratio of acetone to aqueous phase (sample + PVP) volumes was higher than 7, a bulky precipitate settled and was easily separated by decantation. In this case the recoveries were quantitative, which shows that precipitation was complete.

\subsection{Effect of $\mathrm{pH}$ on recoveries of analytes}

The effect of $\mathrm{pH}$ on the recoveries of the mercury, lead and cadmium is shown in Figure 1. If the $\mathrm{pH}$ of the sample and polymer mixture was higher than 6.0, mercury, cadmium and lead were quantitatively recovered with high precision.

Since quantitative recoveries were reproducibly obtained. It can be concluded that mercury ions were completely bound to the polymer and there was no need to wait during steps of the procedures. The effect of initial mercury concentration in the aqueous solution on the removal of $\mathrm{Hg}$ (II) by the PVP polymer is shown in Figure 2. As expected the removal capacity of the polymer increased with increasing initial concentration. The removal of $\mathrm{Hg}$ (II) increased from $2.5 \mathrm{mg} / \mathrm{g}$ to $30.4 \mathrm{mg} / \mathrm{g}$.

\subsection{Adsorption isotherms}

The experimental adsorption isotherms were fitted to mathematical Langmuir and Freundlich isotherms models. For the Langmuir model, the following equation was used:

$$
\mathrm{q}_{\mathrm{eq}}=\mathrm{q}_{\mathrm{m}} \mathrm{C}_{\mathrm{eq}}\left(\mathrm{K}_{\mathrm{d}}+\mathrm{C}_{\mathrm{eq}}\right)
$$

where $\mathrm{q}_{\mathrm{eq}}$ and $\mathrm{C}_{\mathrm{eq}}$ correspond to the milligrams of $\mathrm{Hg}$ adsorbed per one gram of the polymer and the residual $\mathrm{Hg}$ concentration in the solution when in equilibrium (in this case after $5 \mathrm{~min}$ ), and $\mathrm{K}_{\mathrm{d}}$ and $\mathrm{q}_{\mathrm{m}}$ are Langmuir constant and 
maximum capacity of adsorption for this model. Freundlich isotherm constants were calculated with the equation:

$$
\ln \mathrm{q}_{\mathrm{eq}}=\mathrm{n} \ln \mathrm{C}_{\mathrm{eq}}+\ln \mathrm{K}_{\mathrm{F}}
$$

where $\mathrm{K}_{\mathrm{F}}$ and $\mathrm{n}$ are the Freundlich constants characteristic of the polymer system. The Langmuir model is valid for modelling monolayer adsorption onto a homogenous surface with constant adsorption energy; the Freundlich equation posits a heterogeneous surface and considers that molecules attached to a surface site will have an effect on the neighbouring sites [9]. The adsorption data from the different initial concentrations of $\mathrm{Hg}(\mathrm{II}), \mathrm{Cd}(\mathrm{II})$ and $\mathrm{Pb}(\mathrm{II})$ were analyzed in terms of both Langmuir and Freundlich equations at $\mathrm{pH}=6.0$ and $25^{\circ} \mathrm{C}$, and the values obtained for the respective constants are shown in Table 1.

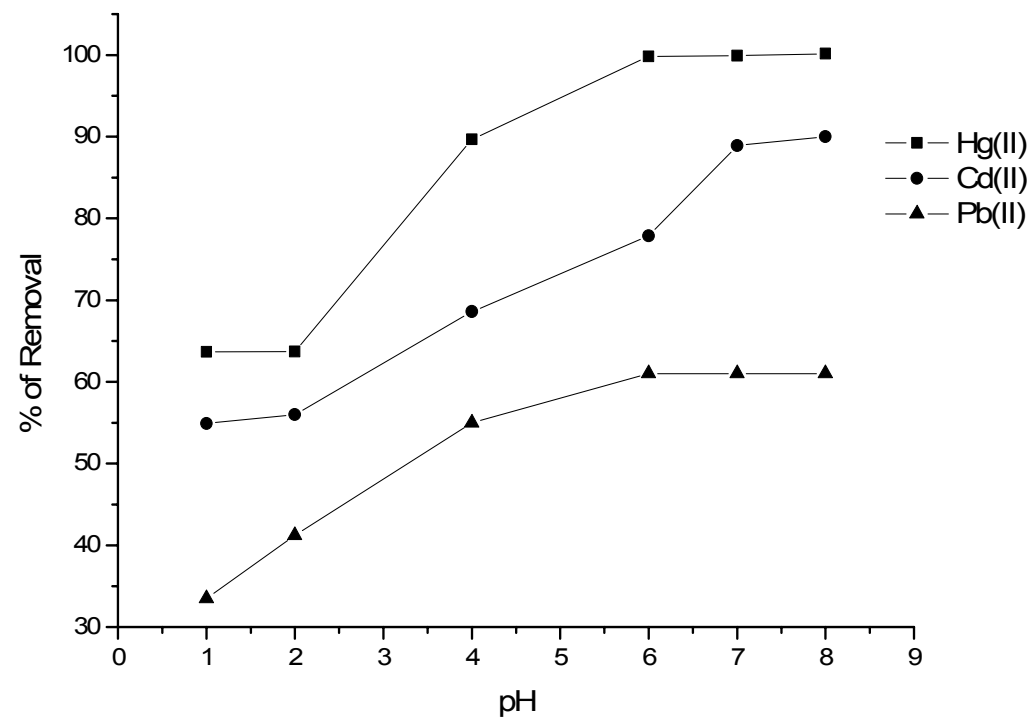

Figure 1: Effect of initial concentration on removal of mercury.

Table 1: $\quad$ Langmuir and Freundlich constants for $\mathrm{Hg}(\mathrm{II}), \mathrm{Cd}(\mathrm{II})$ and $\mathrm{Pb}$ (II) / PVP.

\begin{tabular}{|c|c|c|c|c|}
\hline Metals & $\mathrm{q}_{\mathrm{m}}\left(\mathrm{mg} \mathrm{g}^{-1}\right)$ & $\mathrm{K}_{\mathrm{d}}\left(\mathrm{L} \mathrm{mg}^{-1}\right)$ & $1 / \mathrm{n}\left(\mathrm{L} \mathrm{g}^{-1}\right)$ & $\mathrm{K}_{\mathrm{F}}\left(\mathrm{mg} \mathrm{g}^{-1}\right)$ \\
\hline $\mathrm{Hg}(\mathrm{II})$ & 30.5 & 0.550 & 0.330 & 11.24 \\
\hline $\mathrm{Cd}(\mathrm{II})$ & 22.2 & 0.312 & 0.243 & 9.04 \\
\hline $\mathrm{Pb}(\mathrm{II})$ & 13.3 & 0.180 & 0.122 & 4.22 \\
\hline
\end{tabular}

The Langmuir isotherm equation $\left(\mathrm{r}^{2}=0.9973\right)$ seemed to describe better the adsorption process of $\mathrm{Hg}(\mathrm{II})$ by PVP than the Freundlich isotherm $\left(\mathrm{r}^{2}=0.9910\right)$. the determination coefficients $\left(r^{2}\right)$, used to describe the fitness between the experimental and theoretical models, were high for both equations (Figure 3), and the applicability of both Langmuir and Freundlich isotherms implied that both monolayer adsorption and heterogeneous surface conditions exist under the 
experimental conditions used here, with the latter process prevailing. According to Acar and Malkoc [9], if $0.1<1 / \mathrm{n}<1.0$, the adsorption of an adsorbent on the polymer is favourable. In this study $1 / \mathrm{n}$ was 0.33 , indicating that the polymer can be used effectively for removal of $\mathrm{Hg}$ (II) from aqueous solutions.
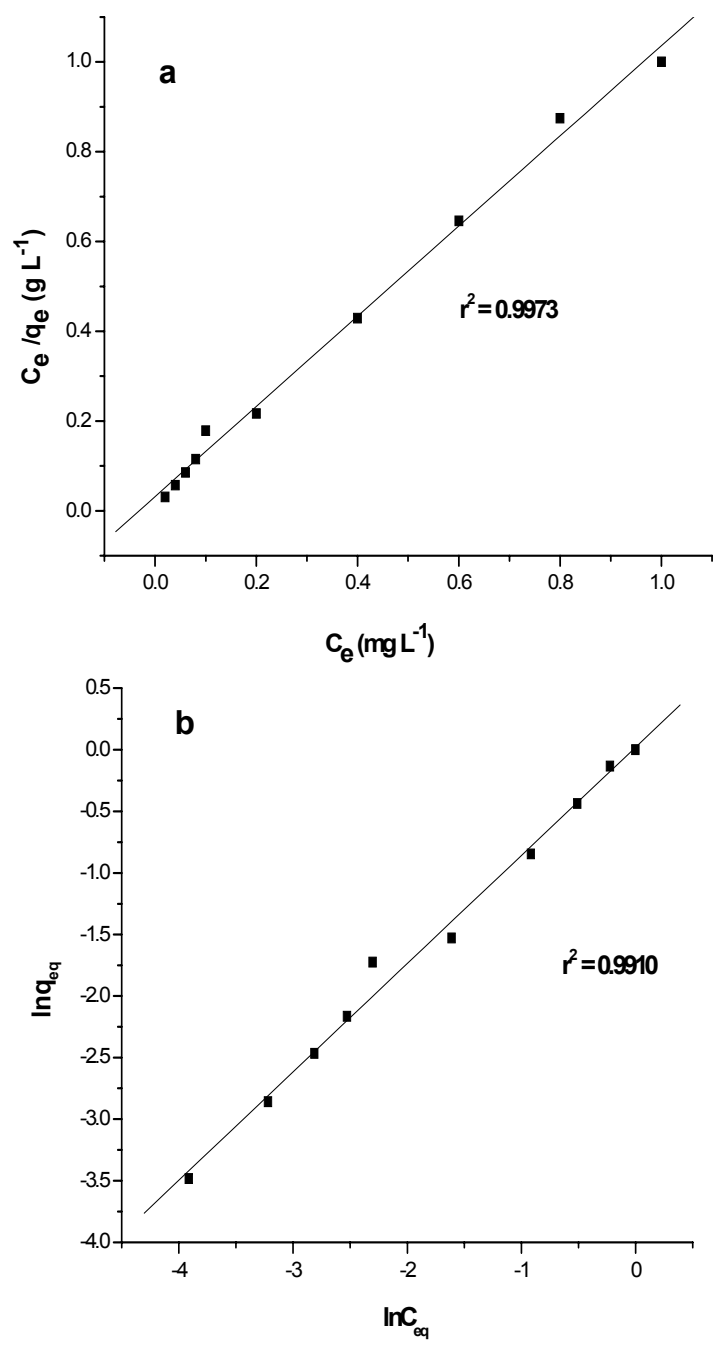

Figure 2: $\quad \operatorname{Hg}$ (II) adsorption isotherm based on the (a) Langmuir and (b) Freundlich models.

\subsection{Removal of $\mathrm{Hg}(\mathrm{II})$ ions from wastewater samples}

The wastewater samples were firstly characterised by ASTM and ISO standard methods. The wastewater samples were found to contain $0.1-5.0$ and $0.05-2.0 \mathrm{mg}$ 
$1^{-1}$ of mercury(II), respectively. Six samples were digested with nitric acid, followed by $\mathrm{pH}$ adjustment and treatment with the poly(vinyl pyrrolidinone) under the optimized conditions described above .Assay of mercury in the final effluents indicates $97.2-99.5 \%$ removal of the original concentrations. The mean standard deviation is $\pm 1.3 \%$. The adsorption capacities were $26.5 \mathrm{mg} / \mathrm{g}$ for $\mathrm{Hg}$ (II), $20.2 \mathrm{mg} / \mathrm{g}$ for $\mathrm{Cd}(\mathrm{II})$ and $15.3 \mathrm{mg} / \mathrm{g}$ for $\mathrm{Pb}(\mathrm{II})$.

\section{Conclusions}

Water soluble polymer, polyvinylpyrroliidinone (PVP) could be successfully applied for the preconcentration and separation of mercury, cadmium and lead from aqueous solutions prior to their analysis by ICP-AES. This method provides the use of numerous water soluble polymers for the removal of toxic elements from the environment which could not been used in column and batch methods. The method offered is simple, fast and precise. No chemicals, other than aqueous polymer solution and acetone, are used in whole procedure. Recoveries were almost quantitative with high precisions in all samples studied because sample and polymer mix spontaneously in the solution phase and the precipitate is dissolved completely. The present study shows the adsorption of $\mathrm{Hg}(\mathrm{II}), \mathrm{Cd}(\mathrm{II})$ and $\mathrm{Pb}$ (II) on the PVP follows the adsorption isotherm models tested, Langmuir and Freundlich isotherm.

\section{References}

[1] Boening, D.W., Ecological effects, transport, and fate of mercury: a general review. Chemosphere, 40, pp. 1335-1351, 2000.

[2] Hoffman(ED), D.J., Hand Book of Ecotoxicology, CRC Press LLC: Baca Raton, FL, pp. 409-464, 2003.

[3] Clarkson, T.W., The toxicology of mercury. Crit. Rev. Toxicol, 34, pp. 369 403, 1997.

[4] Rivas, B. \& Pereira, E.D\& Villoslada, I.M., Water soluble polymers metal ion interactions. Prog. Polm. Sci, 28, pp. 173-208, 2003.

[5] Lloyd-Jones, P.J. \& Rangel-Mendez, J.R \& Streat, M., Mercury sorption from aqueous solution by chelating ion exchange, activated carbon and a biosorbent. Process Saf. Environ. Prot, 82(B4), pp.301-311, 2004.

[6] Mohammed, Z. \& Cano Pavon, J.M. \& Torres deg, A.G., Chelating sorbents based on silica gel and their application in atomic spectrometry. Anal Bioanal Chem, 381, pp. 1103-1113, 2005.

[7] Poole, C.F., New trends in solid phase extraction. Trend Anal. Chem, 22, pp. 362-373, 2003.

[8] Ralph, T.Y., Adsorbents: Fundamentals and Applications, WileyInterscience\& Sons, ING., New York, pp. 18-49, 2003.

[9] Acar, F.N. \& Malkoc, E., The removal of chromium(VI) from aqueous solutions by Fugus Orientalis L. Bioresour. Technol, 94, pp. 13-15, 2004. 